\title{
The Geostationary Remote Infrared Pollution Sounder (GRIPS): measurement of the carbon gases from space
}

M. Schoeberl, R. Dickerson, B. Marshall, M. McHugh, C. Fish, et al.

M. Schoeberl, R. Dickerson, B. T. Marshall, M. McHugh, C. Fish, H. Bloom, "The Geostationary Remote Infrared Pollution Sounder (GRIPS): measurement of the carbon gases from space," Proc. SPIE 8866, Earth Observing Systems XVIII, 886602 (23 September 2013); doi: 10.1117/12.2030907

SPIE Event: SPIE Optical Engineering + Applications, 2013, San Diego, California, United States 


\title{
The Geostationary Remote Infrared Pollution Sounder (GRIPS): Measurement of the Carbon Gases from Space
}

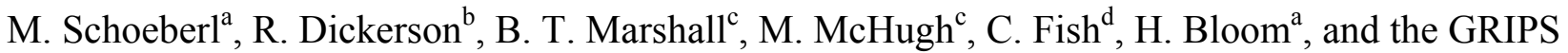 \\ Team ${ }^{\mathrm{e}}$. \\ ${ }^{a}$ Science and Technology Corporation, Hampton, Va, USA; ${ }^{b}$ U. of Maryland, College Park, Md., ,

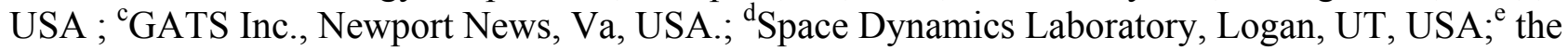 \\ GRIPS Team includes many science and engineering investigators who are on our proposal but are \\ too numerous to include here as co-authors.
}

\begin{abstract}
Climate change and air quality are the most pressing environmental issues of the 21 st century. Despite decades of research, the sources and sinks of key greenhouse gases remain highly uncertain $\left[\mathrm{IPCC}^{1}\right]$ making quantitative predictions of atmospheric composition and their impacts. The Geostationary Remote Infrared Pollution Sounder (GRIPS) is a multi-purpose instrument designed to reduce uncertainty associated with atmospheric radiative forcing. GRIPS will measure will measure greenhouse gases and aerosols - two of the most important elements in the earth's radiation budget. GRIPS will observe carbon dioxide $\left(\mathrm{CO}_{2}\right)$, carbon monoxide $(\mathrm{CO})$, methane $(\mathrm{CH} 4)$, - the carbon gases, nitrous oxide $\left(\mathrm{N}_{2} \mathrm{O}\right)$, water vapor and aerosols with unprecedented precision through the atmosphere. The GRIPS instrument uses gas filter correlation radiometry (GFCR) to detect reflected and thermal IR radiation to detect the gases and the reflected solar radiation in the visible and short-wave infrared bands for aerosols. GRIPS is designed to have sensitivity down to the Earth's surface at $\sim 2-8 \mathrm{~km}$ nadir resolution. GRIPS can resolve $\mathrm{CO}_{2}, \mathrm{CO}$, and $\mathrm{CH} 4$ anomalies in the planetary boundary layer and the free troposphere to quantify lofting, diurnal variations and longrange transport. With repeated measurements throughout the day GRIPS can maximize the number of cloud free measurements determining biogenic and anthropogenic sources, sinks, and fluxes. GRIPS is highly complementary to the Orbiting Carbon Observatory, OCO-2, the geostationary Tropospheric Emissions: Monitoring of Pollution (TEMPO) and Advanced Baseline Imager (ABI) and other existing and planned missions.
\end{abstract}

Keywords: Climate change, air quality, trace gases, gas filer

\section{INTRODUCTION}

In order to address scientific climate and air quality questions of central importance to our planet, our Team is proposing the Geostationary Remote Infrared Pollution Sounder (GRIPS). GRIPS will be the first geostationary instrument to make highly accurate measurements of $\mathrm{CO}_{2}, \mathrm{CH} 4$, and CO. GRIPS will also measure column $\mathrm{O}_{2}$ and $\mathrm{N}_{2} \mathrm{O}$, primarily to identify and correct for aerosols and clouds. Space-based instruments measure these gases already, but pinpointing their emissions has remained beyond the reach of current technology. The increases in emissions of these three carbon containing gases occurring as a result of land-use/land-cover changes, urbanization, and changing technologies in fossilfuel extraction may have dire consequences.

Earth Observing Systems XVIII, edited by James J. Butler, Xiaoxiong Xiong, Xingfa Gu, Proc. of SPIE Vol. 8866, 886602 - (c) 2013 SPIE - CCC code: 0277-786X/13/\$18 - doi: 10.1117/12.2030907 


\subsection{Science Overview}

At the heart of climate change and air quality issues lie the trace gases $\mathrm{CO}_{2}, \mathrm{CH}_{4}, \mathrm{CO}, \mathrm{N}_{2} \mathrm{O}$ and aerosols. Through radiative forcing and/or impacts on ozone and the oxidizing capacity of the atmosphere they have adverse effects on Earth's climate and air quality. Current observations of these pollutants are inadequate to characterize fully their sources, sinks, transport, and impacts, or to forecast accurately health and environmental consequences. With the current crop of operational sensors we cannot answer the following crosscutting questions:

- What are the emissions of $\mathrm{CO}_{2}, \mathrm{CO}$, and $\mathrm{CH}_{4}$ ? How does each one vary diurnally?

- What are the net (production - loss) emissions of $\mathrm{CO}_{2}, \mathrm{CO}$, and $\mathrm{CH}_{4}$ from urban/industrial regions and/or point sources as well as agriculture, wetlands forests, grasslands and semi-arid regions?

- What fraction of $\mathrm{CO}$ emissions are lifted out of a polluted boundary layer and exported?

\section{$1.2 \mathrm{CO}_{2}$}

$\mathrm{CO}_{2}$ dominates radiative forcing in the atmosphere. Atmospheric $\mathrm{CO}_{2}$ has increased from $280 \mathrm{ppm}$ (parts per million by volume) before Industrial Revolution to $390 \mathrm{ppm}$ at present, largely caused by fossil fuel burning and deforestation. Yet, careful analysis reveals that only about half of the anthropogenic $\mathrm{CO}_{2}$ is left in the atmosphere, with the remainder taken up by highly uncertain sinks in the ocean and on land. This uncertainty limits our ability to predict future growth rates for $\mathrm{CO}_{2}$. It is relatively easy to measure $\mathrm{CO}_{2}$ in-situ, as well-recognized time-series testify (e.g. the Keeling curve). The most reliable $\mathrm{CO}_{2}$ measurements currently come from a network of $\sim 100$ NOAA ESRL air sampling stations distributed around the world (Conway et al., 1994). However, the complexity of the biogeochemical cycling of $\mathrm{CO}_{2}$, including its connection to photosynthesis, respiration, ocean uptake and circulation, require a continuous large-scale view of atmospheric $\mathrm{CO}_{2}$ which will be addressed after 2015 by OCO-2 [Crisp et $\mathrm{al}^{2}$; Crisp et al ${ }^{3}$; Miller et al., ${ }^{4}$.

\section{$1.3 \mathrm{CH}_{4}$}

$\mathrm{CH}_{4}$ the second most potent greenhouse gas and a major source of stratospheric water vapor, increased $\sim 1 \% / \mathrm{yr}$ until the 1990's, remained constant and then began to increase again [Dlugokencky et al., ${ }^{5}$. With a wide range of natural (wetlands, clathrates, termites) and anthropogenic (rice paddies, ruminants, landfills, mining and gas operations) sources, quantifying the $\mathrm{CH}_{4}$ budget is notoriously difficult. Extraction of shale gas and oil including hydrological fracturing or "fracking" may be a substantial new source of $\mathrm{CH}_{4}$ in North America and southern Africa [Howarth et al. ${ }^{6}$ ]. $\mathrm{CH}_{4}$ has a relatively short lifetime $(\sim 10 \mathrm{yr})$ so controlling its emissions can have a rapid ameliorating effect. Positive feedback through the reaction between $\mathrm{CH}_{4}$ and the hydroxyl radical $\mathrm{OH}$ means that increases in emissions of $\mathrm{CH}_{4}$ lead to an accelerating tendency for $\mathrm{CH}_{4}$ to accumulate in the atmosphere. Further, as global temperatures increase, biogenic $\mathrm{CH}_{4}$ sources like wetlands, rice paddies and clathrate seepage, react positively. The photochemical cycling of $\mathrm{CH}_{4}$ by $\mathrm{OH}$ produces $\mathrm{CO}$, the other major sink for $\mathrm{OH}$ on a global basis [Thompson, 1992 ; Thompson and Cicerone, $1986^{8}$ ]. Increases in $\mathrm{CH}_{4}$ and $\mathrm{CO}$ singly or together contribute to global tropospheric $\mathrm{O}_{3}$, another strong greenhouse gas.

\section{$1.4 \mathrm{CO}$}

$\mathrm{CO}$, like $\mathrm{CH}_{4}$, has both natural and anthropogenic sources. Globally, the most important natural sources, photochemical oxidation of biogenic hydrocarbons and biomass burning, are strong in the tropics. Anthropogenic emissions of individual countries and sectors (domestic biofuels, energy production, transport) are poorly known. Yet, long-range transport of $\mathrm{CO}$ (see Figure D1.1.1) and its photochemical by-product, $\mathrm{O}_{3}$, are critical factors in trans-boundary and intercontinental flow including to the western US where it has an impact on policy relevant background Criteria Pollutant concentrations [Cooper et al., 2010 ; Jaffe, $2011^{10}$; Lin et al., $2012^{11}$ ]. 


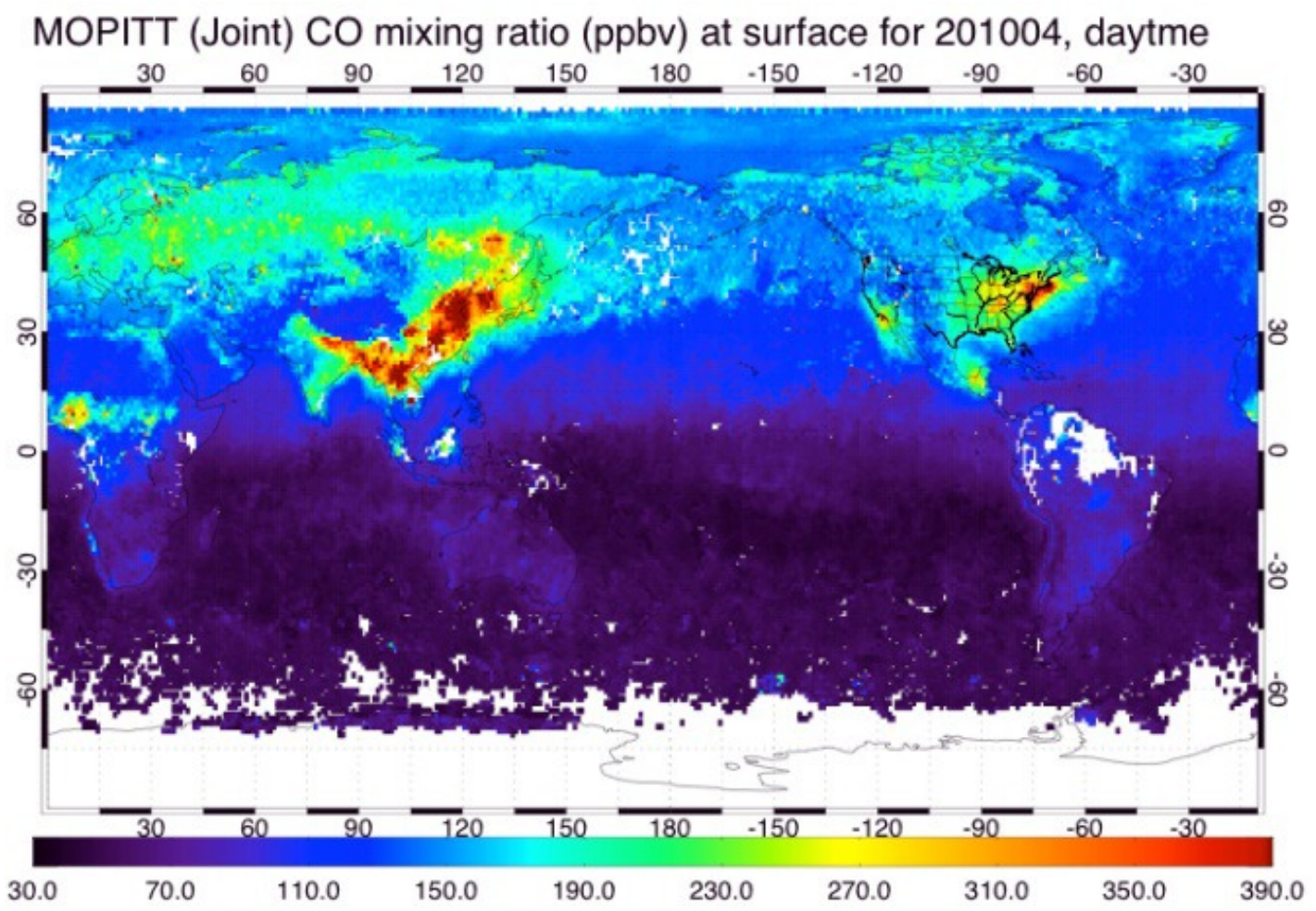

Figure 1 MOPITT average spring measurements of CO using SWIR and MWIR observations. Note the emissions streaming eastward from Asia. These are lower tropospheric amounts. Plumes of CO, lofted from the boundary layer, extend over the ocean. To track plumes extending from land to the ocean, GRIPS includes thermal IR channel.

\subsection{Aerosols}

GRIPS includes aerosol channels. Aerosols are a significant factor in global warming [Bellouin et al., ${ }^{12}$ ] and aerosol forcing is made more complex by the interaction of aerosols and clouds [IPCC, 2007]. Aerosols particles scatter and absorb solar radiation reducing the flux of solar radiation to the surface. Aerosols act as cloud condensation nuclei and can change cloud reflectivity and can alter the hydrological cycle [Twomey, ${ }^{13}$; Rosenfeld and Lensky, ${ }^{14}$ ). Aerosols occur naturally from wind blown desert dust or sea salt. Anthropogenic aerosol sources include urban/industrial pollution and biomass burning. Unlike the carbon gases $\mathrm{CO}_{2}$ and $\mathrm{CH}_{4}$, aerosols are not well mixed in the atmosphere and have a relatively short lifetime. Because of their spatial and temporal variability, the uncertainty of aerosol forcing on climate and the hydrological cycle is on the order of $2 \mathrm{~W} / \mathrm{m}^{2}$ (IPCC ${ }^{1}$ ). Therefore, characterizing global aerosol distribution presents one of our major challenges today (Kaufman, et al. ${ }^{15}$ ). Aerosol production is strongly linked to fires (smoke) and natural sources of $\mathrm{CO}, \mathrm{CO}_{2}$ and $\mathrm{CH}_{4}$. Thus using the aerosol channels combined with the other carbon gas measurements helps us separate the different sources of $\mathrm{CO}, \mathrm{CO}_{2}$ and $\mathrm{CH}_{4}$. Figure 2 shows MODIS Aqua global aerosol optical depth (AOD) for May 25, 2002. MODIS aerosol measurements over the ocean follow the algorithm developed for AVHRR. Over land, aerosol retrievals are more complicated due to the varying albedo of the surface [Remer et al., ${ }^{16}$ ]. GRIPS aerosol measurements require a short wave infrared channel $(2.13 \mu \mathrm{m})$ that is insensitive to aerosols. - this channel can also double as a fire sensing channel. 


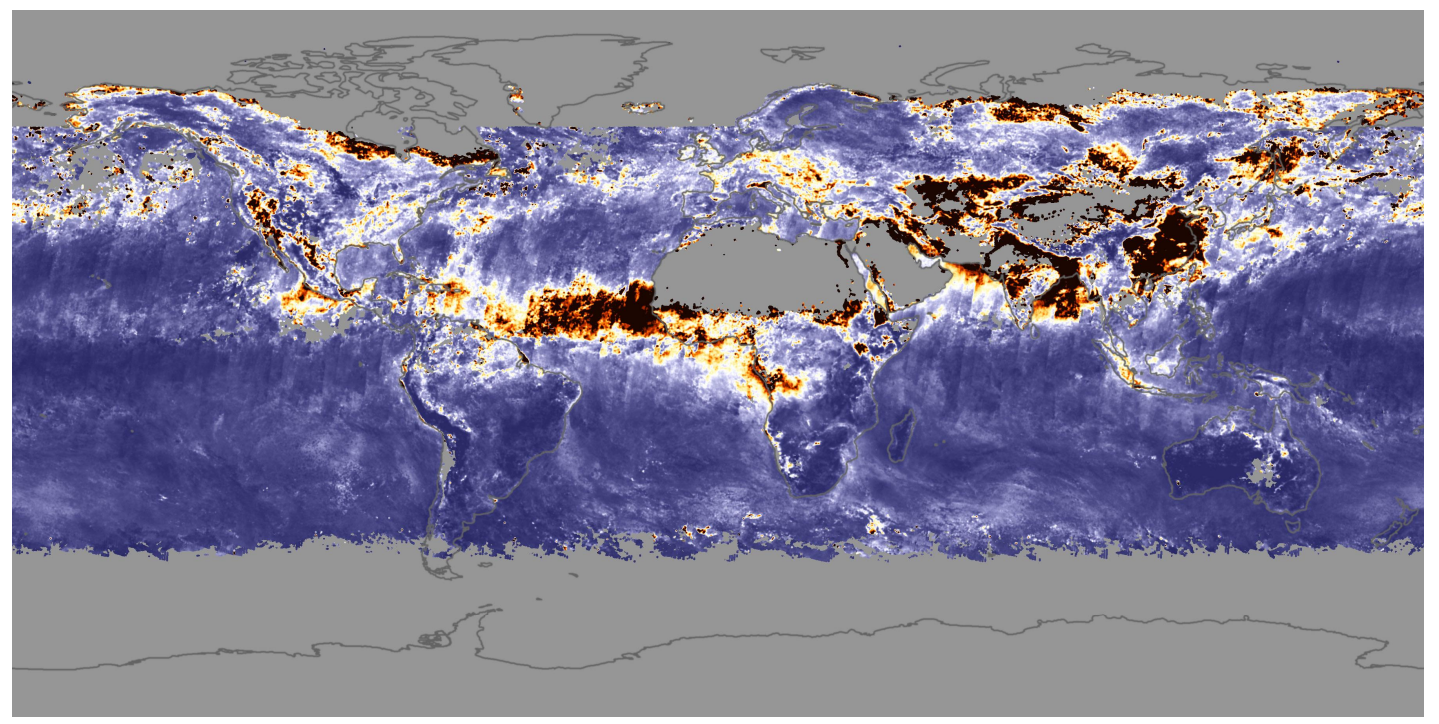

Figure 2. MODIS aerosol AOD map for May 25, 2002 from the NASA Earth Observatory. Aerosol transport over the ocean from North Africa to South America and from Asia across to the Pacific is apparent. MODIS aerosol retrievals over high albedo regions have improved with each Collection. Aerosols channels on GRIPS will provide good correlation with fires and emissions of $\mathrm{CO}$ and $\mathrm{CH}_{4}$.

\section{INSTRUMENT DEVELOPMENT}

\subsection{Existing Measurement Approaches}

This section reviews instruments already in orbit or planned as well as the procedures to obtain accurate measurements and to meet the specific science objectives listed in Table 1. The GRIPS instrument will provide highly accurate measurements $\mathrm{CO}_{2}, \mathrm{CH}_{4}, \mathrm{~N}_{2} \mathrm{O}, \mathrm{CO}$, and aerosol measurements and when combined with carbon cycle and chemical transport models it will allow the determination of the emissions and export of these trace gases as well as associated pollutants. Temporal and spatial resolution for most of the current instruments is inadequate to resolve source information, except for $\mathrm{CO}_{2}$ from OCO, and GRIPS will complement those measurements.

Among instruments specifically developed for $\mathrm{CO}_{2}$ (and $\mathrm{CH} 4$ ) retrievals low earth orbiting GOSAT has produced data since 2009, although with relatively low precision and large footprint compared to OCO-2. A common limitation for GOSAT and OCO-2 is that km-scale resolution is obtained only as infrequent snapshots (1/2-week to 2 weeks) under cloud free conditions. Including cloud and aerosol contamination means that the effective temporal resolution will be lower. Couple this limitation with rapid transport, and the low revisit frequency of an individual source further compromises the ability of these satellites to infer fluxes. Miller et al. ${ }^{4}$ and Crisp et al. ${ }^{3}$ report that precision of better than $2 \mathrm{ppm}$ is required to resolve monthly or annual variations in $\mathrm{X}_{\mathrm{CO} 2}$. They further report, based on correlation length, that this precision over an area of about $10,000 \mathrm{~km}^{2}$ should be sufficient to constrain the $\mathrm{C}$ flux enough to greatly improve global C models. OCO-2 will provide global coverage of $\mathrm{X}_{\mathrm{CO} 2}$ at $\sim 1: 30 \mathrm{PM}$ local standard time with $\sim 3 \mathrm{~km}^{2}$ resolution once every 16 days. At that resolution, $\sim 24 \%$ of the pixels will be cloud free providing a $1-2 \mathrm{ppm}(\sim 0.3 \%)$ precision with spatial resolution of 1000x1000 km. Although OCO-2 will have a higher precision for individual column measurements than GRIPS and will provide global coverage, GRIPS will be able to harvest a substantially higher number of cloud free pixels and provide better areal coverage. In short, we believe that the two measurement systems are highly complementary. The background amount of $\mathrm{CH}_{4}$ is large and requirements for pinpointing sources are similar to those for $\mathrm{CO}_{2}$. Frankenberg et al. ${ }^{17}$ reported both technical limitations of SCIAMACHY sensing of $\mathrm{CH}_{4}$ (cloud 
contamination at high latitudes, poor detection over ocean) and surprisingly high values over tropical forests in Africa and South America. GRIPS will provide vastly improved measurements of methane concentrations and column amounts and will be able to further quantify the results from SCIAMACHY. While GRIPS duplicates some of the aerosol channels on the Advanced Baseline Imager (ABI), we believe that we should minimize the dependence of our measurement suite on other instruments.

\begin{tabular}{|c|c|c|c|c|c|}
\hline INSTRUMENT & MEASUREMENT & BANDS & $\begin{array}{l}\text { PRECISION } \\
\text { (PPM) }\end{array}$ & $\begin{array}{l}\text { SPATIAL } \\
\text { RESOLUTION }\end{array}$ & $\begin{array}{l}\text { TEMPORAL } \\
\text { RESOLUTION }\end{array}$ \\
\hline MOPITT & CO Total Column & NIR & $\sim 0.01$ & $22 \mathrm{~km}$ & $\sim 3$ days \\
\hline GOSAT & $\mathrm{CO}_{2}$ Total Column & SWIR & 4 & $10 \mathrm{~km}$ - no swath & $\sim 3$ days / glint \\
\hline OCO-2,3 & $\mathrm{CO}_{2}$ Total Column & SWIR & 1 & $1.5 \mathrm{~km}$ - no swath & 16 days /glint \\
\hline \multirow{2}{*}{ MODIS } & AOD Ocean & \multirow{2}{*}{$\begin{array}{l}\text { Visible and } \\
\text { SWIR }\end{array}$} & $\Delta \tau= \pm 0.03 \pm 0.05 \tau$ & \multirow{2}{*}{10 km (nadir) } & \multirow{2}{*}{$\sim 1$ day } \\
\hline & AOD Land & & $\Delta \tau= \pm 0.05 \pm 0.15 \tau$ & & \\
\hline VIIRS & Aerosol & $\begin{array}{l}\text { Visible and } \\
\text { SWIR }\end{array}$ & & 6 km (nadir) & $\sim 1$ day \\
\hline AIRS & $\begin{array}{l}\mathrm{CO}_{2} \mathrm{MT} \\
\mathrm{CH} 4 \mathrm{MUT} \\
\mathrm{CO} \mathrm{MT} \\
\end{array}$ & $\begin{array}{l}\text { MWIR/LWIR } \\
\text { MWIR } \\
\text { MWIR } \\
\end{array}$ & $\begin{array}{l}1-2 \\
0.03-0.04 \\
\sim 0.01 \\
\end{array}$ & $\begin{array}{l}\sim 90 \mathrm{~km} \\
45 \mathrm{~km} \\
45 \mathrm{~km} \\
\end{array}$ & $\sim 1$ day \\
\hline IASI & $\begin{array}{l}\mathrm{CO}_{2} \mathrm{UT} \\
\mathrm{CO} \mathrm{MT}\end{array}$ & $\begin{array}{l}\text { MWIR/LWIR } \\
\text { MWIR }\end{array}$ & $\begin{array}{l}2 \\
\sim 0.01\end{array}$ & $\begin{array}{l}\sim 22 \mathrm{~km} \text { (Binned } \\
\text { at } 500 \mathrm{~km} \times 500 \\
\mathrm{~km}) \\
\sim 22 \mathrm{~km}\end{array}$ & $\begin{array}{l}\sim 31 \text { days } \\
\sim 1 \text { day }\end{array}$ \\
\hline ABI & Aerosols clouds & Vis \& SWIR & $\begin{array}{ll}\text { same } & \text { as } \\
\text { MODIS } & \\
\end{array}$ & $1 \mathrm{~km}$ & $4 \mathrm{hrs}$ \\
\hline TES & $\begin{array}{l}\mathrm{CO}_{2} \mathrm{MT} \\
\mathrm{CO} \mathrm{MTL} \\
\end{array}$ & $\begin{array}{l}\text { MWIR } \\
\text { MWIR } \\
\end{array}$ & $\begin{array}{l}5 \\
0.01-0.02 \\
\end{array}$ & $\begin{array}{l}\sim 10 \mathrm{~km}-\text { no } \\
\text { swath }\end{array}$ & 16 days \\
\hline \multirow[t]{2}{*}{ GRIPS } & $\begin{array}{l}\mathrm{CO}_{2} \text { Column/PBL } \\
\mathrm{CH}_{4} \text { Column/PBL } \\
\mathrm{CO} \text { Column/PBL } \\
\mathrm{H}_{2} \mathrm{O} \text { Column }\end{array}$ & $\begin{array}{l}\text { SWIR } \\
\text { SWIR } \\
\text { SWIR/MWIR } \\
\text { SWIR }\end{array}$ & $\begin{array}{l}1-10 \\
0.004-0.040 \\
0.003-0.012 \\
30 \%\end{array}$ & $<8$ km (nadir) & \multirow[t]{2}{*}{$1-2 \mathrm{hr}$} \\
\hline & $\begin{array}{l}\text { AOD Land \& Ocean, } \\
\text { Cirrus detection }\end{array}$ & Vis \& SWIR & $\begin{array}{l}\text { same as } \\
\text { MODIS }\end{array}$ & $<4 \mathrm{~km}$ (nadir) & \\
\hline \multicolumn{6}{|c|}{$\begin{array}{l}\text { Notes: (1) All instruments above in polar orbit except for GRIPS, which will be in a GEO orbit. (2) NIR= Near IR, } \\
\text { SWIR= Shortwave IR, MWIR=Mid-wave IR, LWIR= Long-wave IR. ( } 3 \text { ) Over water OCO-2 and GOSAT can use the } \\
\text { glint. (4) MUT= Mid-to-Upper Troposphere, UT=Upper Troposphere, MT= Mid-Troposphere, MLT=Mid-to-Lower } \\
\text { Troposphere, PBL= Planetary Boundary Layer }\end{array}$} \\
\hline
\end{tabular}

\subsection{Cloud clearing}

The most significant advantage of the geo orbit for remote sensing the surface is cloud clearing. What we mean by cloud clearing is that multiple measurements can be made during the day, and since clouds move, the probability of viewing a clear scene is greatly increased. We have performed simple cloud clearing analyses over views from Asia, America and European sectors using GOES 90 minute cloud data to analyze the frequency of surface observations. Figure 3 shows the example for Asia - the other sectors show similar results. Typically the scene is about $30 \%$ clear (probably clear pixels). Because each scene is slightly different - clouds move, we can accumulate clear pixels as more observations are made. The accumulation of clear pixels is shown in the dotted 
lines in Figure 3. Because the LEO measurements are made once a day, the accumulation of clear [pixels is much slower. In this example, at the end of 5 days, the GEO instrument has acquired a nearly $75 \%$ probably clear scene. In contrast, the LEO instrument has accumulated only a 50\% "probably clear" scene after 5 days assuming that the LEO instrument is like MODIS and sampling each pixel once a day. . If the LEO instrument looks at each pixel only once every 15 days then it will take 75 days to reach $50 \%$ "probably clear."
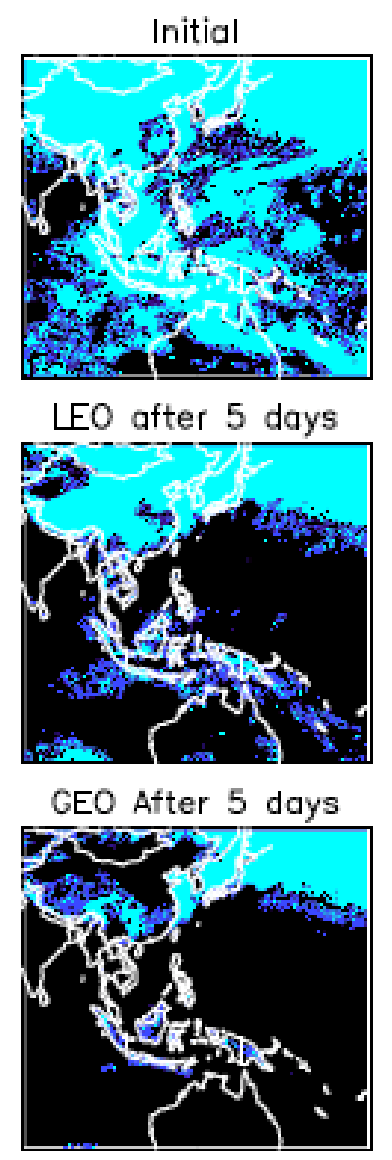

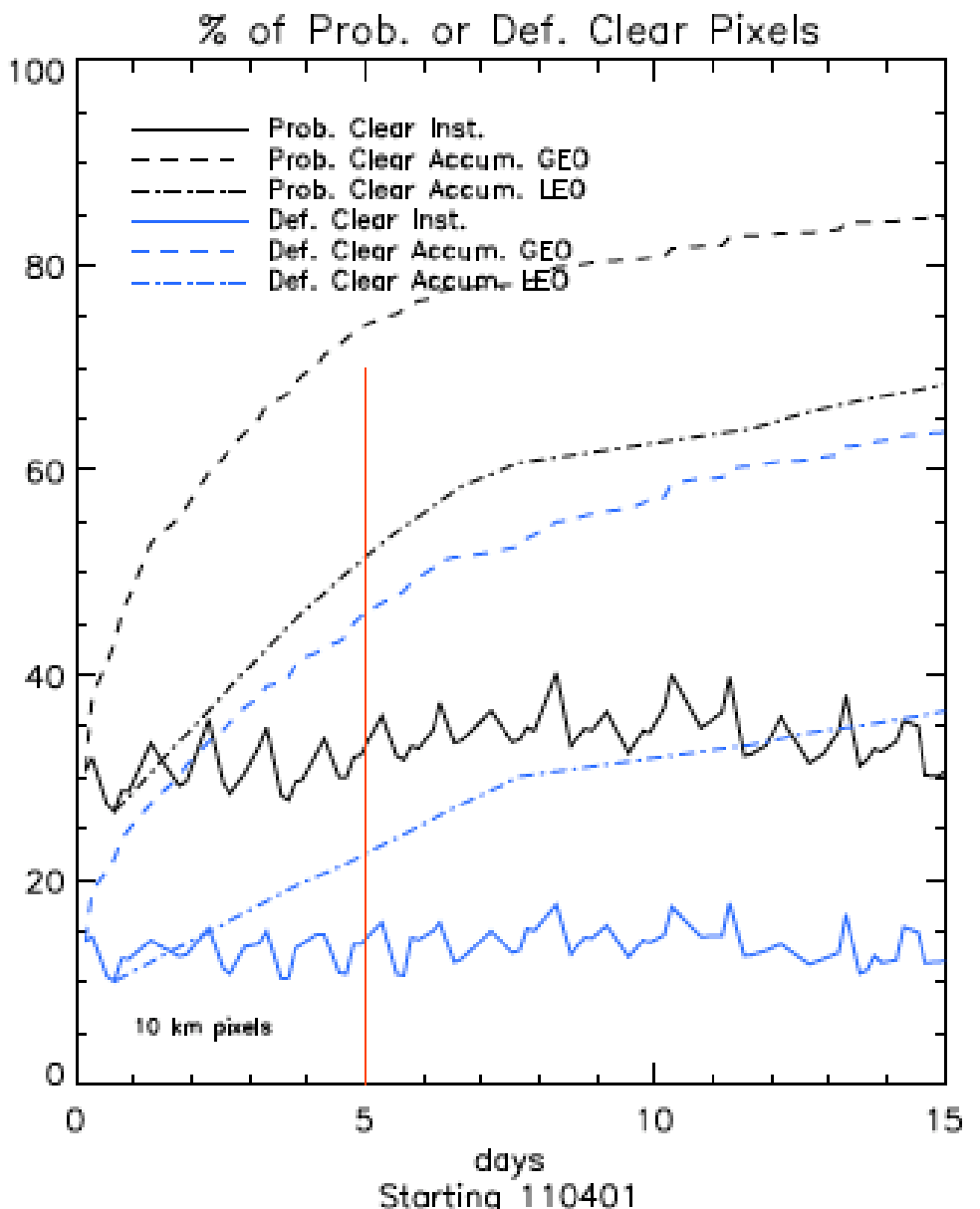

Starting 110401

Figure 3 Accumulated and instantaneous fraction of probably clear and definitely clear pixels vs. time starting April 2011 over Asia. Accumulating probably (black) clear pixels from Geo clears almost $75 \%$ of the region in 5 days while LEO clears only $50 \%$. Maps show the cleared region (black). For definitely clear (blue) accumulated pixels, GEO clears $45 \%$ in 5 days, while LEO clears only $20 \%$ in 5 days.

This advantage of GEO for remote sensing cannot be overemphasized. The earth system production of methane, $\mathrm{CO}_{2}$ and $\mathrm{CO}$ varies strongly with season and a sub-monthly sampling at high spatial resolution is required to answer the science questions. While LEO orbits provide global coverage, unless a constellation of satellites is used, the high time resolution of the GEO instrument provides an unmatched capability. 


\subsection{GRIPS Measurement Approach}

GRIPS is designed to use reflected solar short wave IR (SWIR) as a radiation source because (1) $\mathrm{CO}_{2}, \mathrm{CH}_{4}$, and $\mathrm{CO}$ all have distinct absorption bands in the $\sim 2 \mu \mathrm{m}$ SWIR region where thermal IR is minimal and reflected IR dominates (2) this spectral region has low Rayleigh scatter so solar radiation reaches the surface. For viewing over the oceans where albedo is low (and for nighttime measurements) we add a $4.2 \mu \mathrm{m}$ MWIR CO channel, as in AIRS and MOPITT. MOPITT also had SWIR channels but with rapidly changing scene albedo at LEO the retrievals proved challenging. This albedo issue does not exist for GEO measurements since we constantly view the same scene. (3) From GEO, SWIR measurements can be made when the solar zenith angle is $<90^{\circ}$; however, our error estimates suggest that the most useable measurements occur when the zenith angle is $<70^{\circ}$. Under these conditions, we can make up to 8 measurements per day during summer at high latitudes (Table 1). This frequency of measurement allows us to increase the number of clear pixel samples and increase $\mathrm{S} / \mathrm{N}$ by averaging more measurements. Measurements poleward of $60^{\circ}$ from GEO sensors are usually at too steep an angle to be useful.

For aerosol measurements we pick the wavelengths used by MODIS (see Kaufman et al. ${ }^{18}$ ). The aerosols-over-land algorithm (Remer et al., ${ }^{16}$ ) uses $0.47,0.66$ and $2.13 \mu \mathrm{m}$. In addition to those wavelengths, MODIS uses 0.86 in the aerosols-over-ocean algorithm. We add $0.75 \mu \mathrm{m}$ as an additional aerosol channel and $1.38 \mu \mathrm{m}$ for thin cirrus detection. Figure 4 below shows the GRIPS channels and absorption features.

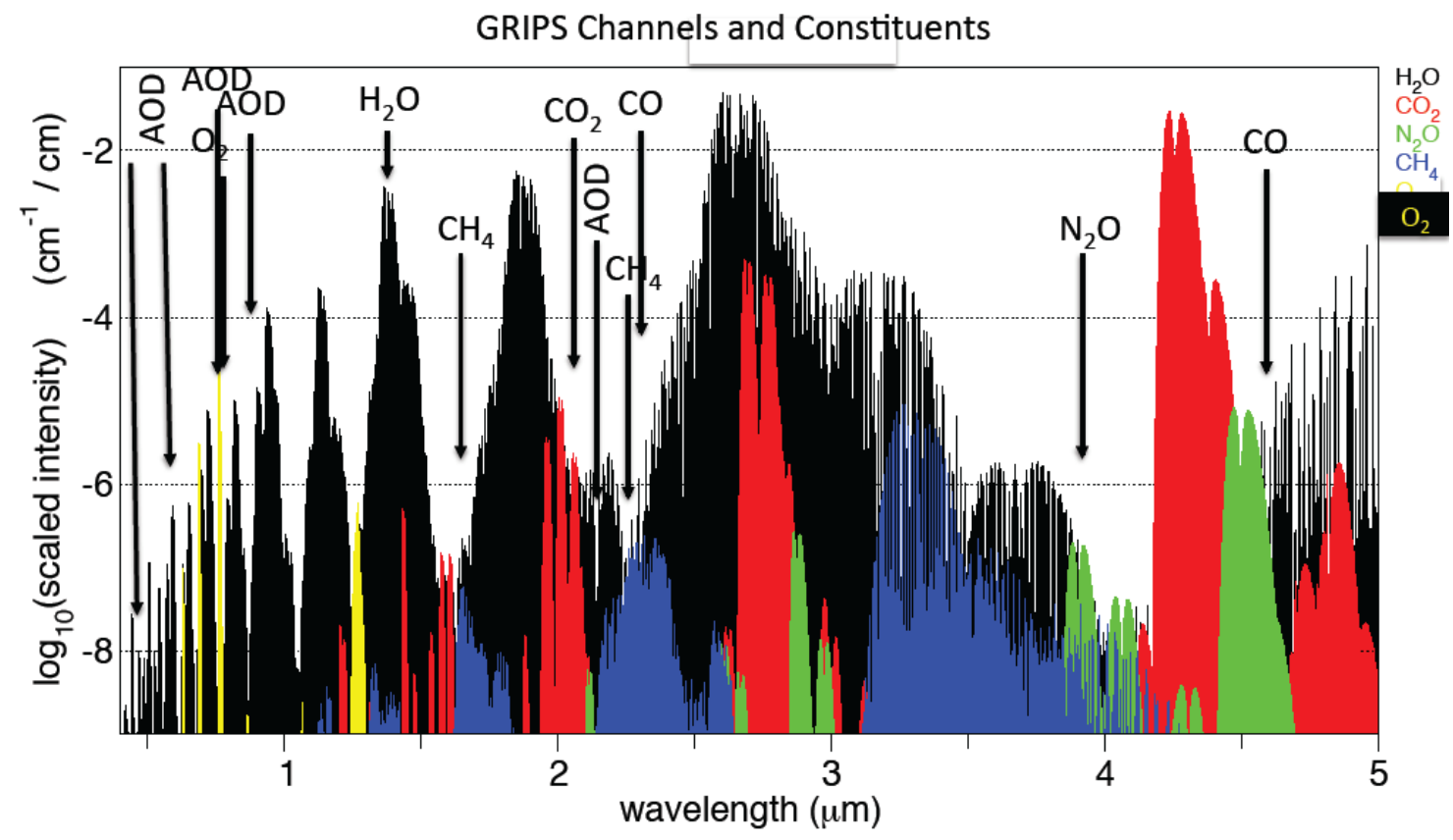

Figure 4. GRIPS channels are chosen to maximize absorption features in the spectral range 0.4-5 $\mu \mathrm{m}$ and minimize interference by water. The spectrum is scaled by atmospheric abundance. Specific lines for the species are shown using the color legend on the right. Arrows with labels show where the GRIPS instrument has channels. AOD represents aerosol optical depth (thickness) measurements. Other gases are labeled. Because $\mathrm{CO}$ ambient concentration is not in our model atmosphere we do not show $\mathrm{CO}$ 
The GRIPS instrument design ensures sufficient accuracy and sensitivity to produce profiles and trace gas column content down to the Earth's surface. The GEO orbit enables GRIPS to sample $\mathrm{CO}_{2}, \mathrm{CH}_{4}$, and $\mathrm{CO}$ at a spatial resolution of $<10 \mathrm{~km}$ every 1-2 $\mathrm{hr}$ and to meet the goals of determining source strengths as described in Section D.1 as well as observing diurnal changes in emissions. For some species, resolving concentrations within transport layers and the PBL will be possible. In addition, surface pressure knowledge to within $\sim 1 \mathrm{hPa}$ is required to remove atmospheric mass column changes due to weather systems and topography. Anticipated data products: Our Level 1 (L1) data products are geo-located, time-stamped instrument radiances. Our Level 2 (L2) retrieval algorithm will run in two modes, quick look (QL) - providing users with Near Real Time data, and the Standard Product retrieval that will use analyzed meteorological and other metadata not available in near real time. The QL product is designed for rapid delivery and serves as a check on instrument performance. The QL algorithm will be for pixels that are "probably clear" according to our $\mathrm{O}_{2}, \mathrm{~N}_{2} \mathrm{O}$, and aerosol band observations since that assumption simplifies the computation. The Standard Product algorithm will be run for all pixels and will also use information from the $\mathrm{N}_{2} \mathrm{O}$ and A-band channels as well as ancillary cloud and meteorological data. This product will be available several days after the QL product. We will also produce a rolling data composite that will average clear sub-pixel data pixels over 16 days for $\mathrm{CH} 4$ and $\mathrm{CO}_{2}$.

\subsection{The GRIPS Instrument}

GRIPS is a gas-filter correlation radiometer (GFCR). The GFCR technique uses a sample of the target gas, or a vicarious absorber, to filter the radiation coming from the observed scene. The difference in the intensity of light traveling through a vacuum path and through the gas filter is proportional to the amount of gas between the instrument and the scene. Using pressure broadening of the spectral lines, gas filters with different pressures can be used to extract altitude profile information.

There are several practical reasons to choose a GFCR for the types of measurements needed to answer the science questions above. First, the GFCR is a relatively simple instrument with few moving parts, making it ideal for satellite applications. Second, the GFCR is capable of making quick measurements, unlike, for example, the FTIR that requires staring at the target. This makes the GFCR ideal for nadir-viewing applications. Third, since GFCR is a radiometer, high signal to noise (S/N) ratios can be achieved because the GFCR makes maximum use of the available photons. Fourth, even though the GFCRs are radiometers, they have very high spectral selectivity of the gas of interest with very high resolving power (> 105). Consequently, GFCRs have minimal spectral interference by other gases. Fifth, GFCR is a well-understood technology, as GFCRs have been used for over four decades in the remote sounding of the earth and other planets (Abel et al. ${ }^{19}$; Drummond et al. ${ }^{20}$; Tolton and Drummond ${ }^{21}$ ). The disadvantage of the GFCR is that it cannot be applied to unstable gases (e.g. $\mathrm{NO}_{2}, \mathrm{O}_{3}$ ) or gases with insufficient absorption in the spectral region of interest to provide adequate signal modulation (e.g. $\mathrm{N}_{2}$ ) using a cell of reasonable length (20 cm for GRIPS). Space borne instruments of this type have a long heritage with a history of reliability (e.g. HALOE, MOPITT).

GRIPS is designed to operate from geostationary orbit $(\sim 36,000 \mathrm{~km})$. The GRIPS instrument uses a 2-axis gimbal that provides $> \pm 15^{\circ}$ of full instrument movement in the lateral directions of the spacecraft nadir deck. This provides the necessary positioning on the earth image, and scans to cold space and positions in lunar path for calibration of offsets, balance and FOV matching. Active pointing control of the GRIPS instrument is not required after movement by the gimbal to a desired position given expected spacecraft attitude knowledge and repeatability of $5 \operatorname{arcmin}(1 \sigma)$ and stability during 100-second samples of \pm 5 arcseconds $(1 \sigma)$. On-orbit GRIPS pointing knowledge can be very accurately inferred from image analysis. Because the multi-beam signals are taken simultaneously with identical FOVs, image stability is not a critical performance factor. Image jitter and drift only smear the signals, slightly degrading spatial resolution, e.g. a 5 arcsecond drift imparts $0.9 \mathrm{~km}$ smear taking a nominal $8 \mathrm{~km}$ footprint to nearly $9 \mathrm{~km}$. 
The GRIPS instrument comprises nine telescope bundles, each bundle consists of four co-aligned optical paths/radiometer telescopes where each of the FOVs common to each telescope are focused onto separate quadrants of an FPA (Teledyne HAWAII H2RG detectors). The seven optical channels are laid out in a square shape as seen in Figure 5 where all channels, with the exception of the $\mathrm{O}_{2}$ A-band and aerosol bundle, are implemented as GFCR radiometers. The $\mathrm{O}_{2} \mathrm{~A}$-band is unique to the design in that it is implemented without the gas cell. The FPAs are housed in a Dewar shell that is cryogenically cooled by dual mini cryocoolers. Teledyne Sidecar FPA ASICs provide the clock and bias signals to drive the FPAs, as well as the image digitization channels. The ASIC electronics are mounted outside the Dewar shell in an electronics box that is thermally isolated but in close proximity (i.e., side of the instrument) to the Dewar shell to minimize tape cabling length between the ASICs and FPAs.

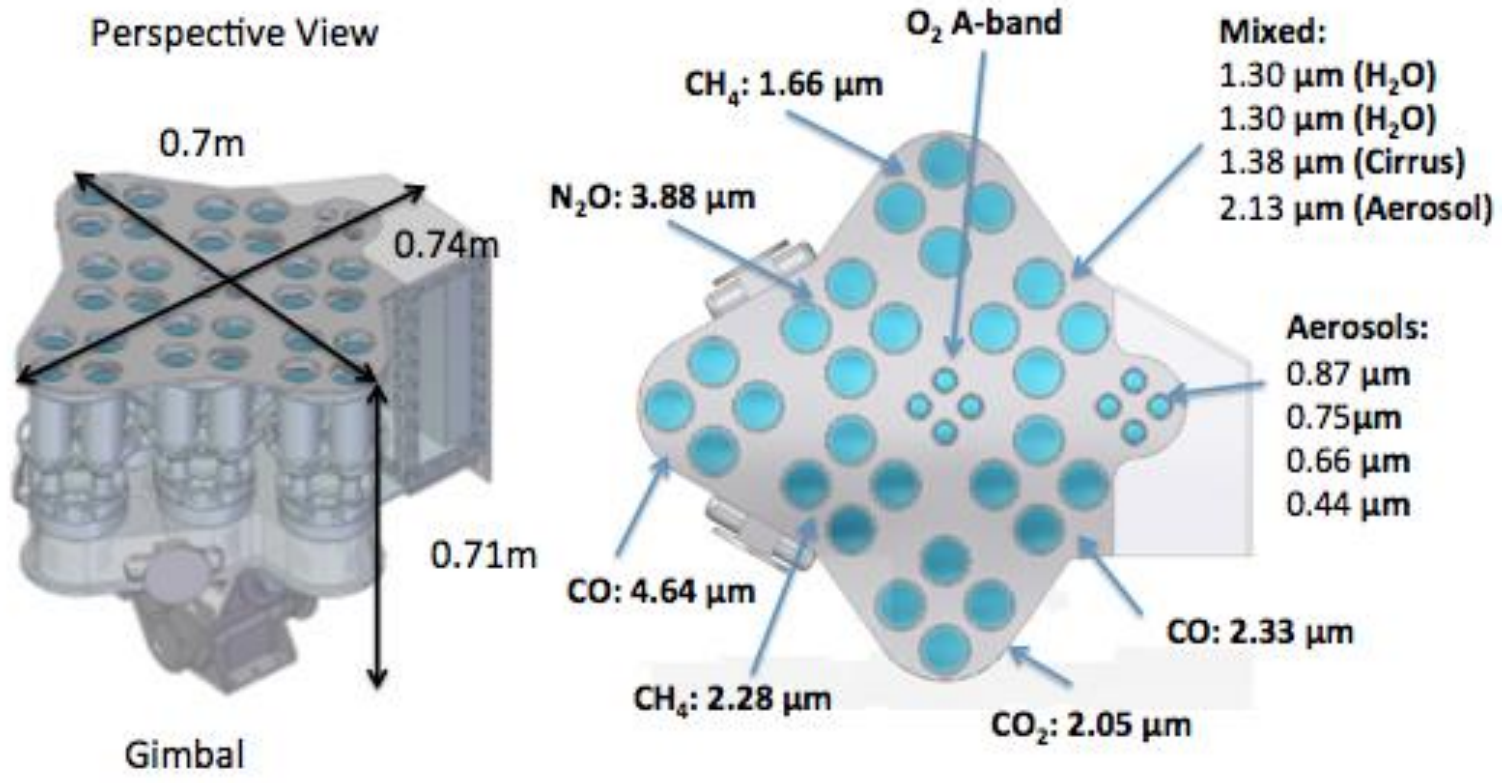

Figure 5. The GRIPS instrument comprises nine telescope bundles (seven GFCR) each consisting of four coaligned optical paths/radiometer telescopes. The optics and FPAs are cooled by cryocoolers. The entire system moves in tandem to the varying GRIPS look positions by a 2 -axis gimbal. The warm electronics are fixed on the instrument deck outside of the Dewar shell.

The seven GFCR radiometer telescope paths have five $\mathrm{cm}$ apertures, a first focus fieldstop, f/16.9 reimaging optics, and two narrow bandpass spectral filters. The spectral filter outside the dewar will be held to the same temperature as the optics and the spectral filter inside the dewar will be held close to the detector temperature. The image of each optical path is folded to a quadrant of the FPA via two planar mirrors - the second being in the shape of a four-sided pyramid - one face for each path. In each channel, light in three of the four optical paths passes through a $10 \mathrm{~cm}$ long gas cell containing a mixture of the target trace gas at different pressures. Light entering the fourth optical path passes through a vacuum cell. Light in each path is then imaged to a first focus containing a 
square field-stop which defines the $1.15 \times 1.15^{\circ} \mathrm{FOV}$. Following the field stop, the light passes through reimaging lenses and then is folded and filtered before it focuses onto separate quadrants of the FPA as square shaped images defined by the field-stop. The NIR and visible band channels are similar to the GFCR channels, minus the use of a gas cell. These channels use $2 \mathrm{~cm}$ apertures and f/42.2 reimaging optics. The GEO advantage along with pixel aggregation affords with very high S/N. Table 2 summarized the radiometric budget for GRIPS for low and high signals for the MWIR, SWIR, NIR, and visible bands.

Table 2. GRIPS Instrument Radiometric Budget

\begin{tabular}{|c|c|c|c|c|c|c|}
\multirow{2}{*}{ PARAMETER } & \multicolumn{4}{|c|}{ VALUE (L=Low signal; H=High signal) } \\
\cline { 2 - 7 } & \multicolumn{2}{|c|}{ MWIR } & \multicolumn{2}{c|}{ SWIR } & \multicolumn{1}{c|}{ NIR and Visible } \\
\cline { 2 - 7 } & L & H & L & H & L & H \\
\hline Scene flux (phot/s/pixel) & $1.2 \mathrm{e} 4$ & $9.8 \mathrm{e} 5$ & $2.0 \mathrm{e} 4$ & $1.9 \mathrm{e} 6$ & $8.5 \mathrm{e} 3$ & $7.2 \mathrm{e} 5$ \\
\hline System Efficiency SE & $50 \%$ & $50 \%$ & $50 \%$ & $50 \%$ & $50 \%$ & $50 \%$ \\
\hline Single Pixel S/N (1 second) & 77.5 & 700 & 100 & 975 & 65.2 & 600 \\
\hline Single Pixel S/N (100 seconds) & 775 & 7000 & 1000 & 9750 & 652 & 6000 \\
\hline 100 Pixel S/N (100 seconds) & 7750 & 70000 & 10000 & 97500 & 6520 & 60000 \\
\hline
\end{tabular}

Note: Noise from dark current, internal emission and readout insignificant. Temporal averaging improves $\mathrm{S} / \mathrm{N}$ by root (seconds). Aggregation of $\mathrm{N}$ pixels improves $\mathrm{S} / \mathrm{N}$ by $\operatorname{root}(\mathrm{N})$. For daytime over land, $\mathrm{S} / \mathrm{N}>3 * \mathrm{~L}$.

\subsection{GRIPS Data analysis}

GRIPS data will be transmitted to ground stations on a regular schedule and processed to produce time and location tagged radiance data. The radiance data will be analyzed by a retrieval system to infer total column content and volume mixing ratio profiles of $\mathrm{CO}, \mathrm{CO}_{2}$, and $\mathrm{CH}_{4}$. In addition to these primary measurements, column abundance of $\mathrm{O}_{2}, \mathrm{~N}_{2} \mathrm{O}$, and $\mathrm{H}_{2} \mathrm{O}$ will be calculated by scaling a-priori profiles to aid determination of cloud contaminated scenes and improve modeling of water vapor. To aid analysis of aerosol and cloud effects, GRIPS also includes channels that measure radiance in the aerosol bands and for cirrus detection as used by MODIS. We do not discuss the aerosol algorithm in this paper but will use approached similar to those described in Remer et al. ${ }^{16}$ for MODIS. We also have two cells of a quad devoted to measuring the water vapor column using HF as a filter.

Each channel of GRIPS (except the aerosol and $\mathrm{O}_{2}$ channels) provides a vacuum path signal, $E_{\mathrm{v}}$, and up to 3 balanced gas path signals: $E_{1}, E_{2}$ and $E_{3}$. To maximize sensitivity to the target gas, we form three normalized differences signal,

$$
D_{i}=\frac{E_{i}-E_{v}}{E_{v}}
$$

for each gas cell path, $i=1$ to $3 . D_{i}$ is highly sensitive to the target gas, but does contain minor contributions from other gases. These interfering species are either simultaneously retrieved from other channels, or a standard climatology is assumed. Spectrally broad modulations such as those due to source variations and aerosol attenuation are nearly eliminated by tuning the spectral bandpass to de-correlate these from the modulation induced by the gas cell. This is effectively accomplished when the gas-cell absorption features are evenly distributed across the bandpass. This, in combination with the statistical averaging advantages of geostationary observations, nearly eliminates problems of scene and spectral albedo variations encountered, for example, by MOPITT (Deeter et al. ${ }^{22}$ ).

The gas correlation measurements sense absorption through the entire path length of light from the Sun to the instrument. Scattering from clouds and aerosols can increase the effective path length significantly, so we need an accurate proxy for the mean path length of each observation. For this we use the 4 broad spectral bands on and near the 
$\mathrm{O}_{2}$ A-band $(0.765 \mu \mathrm{m})$. The resulting differential measurement provides an excellent measure of the variation in the mean photon path (Mitchell and O'Brien, ${ }^{23}$ ). And since the thermal infrared channels (3.88 and $\left.4.64 \mu \mathrm{m}\right)$ include contributions from both thermal emission and solar backscatter, the surface albedo must be included in the retrieval model to properly apportion these components.

The signal to noise estimates given in Table 2 quantify expected measurement error, but an accurate evaluation of the retrieval system performance must include a complete error analysis of the sort described by Rodgers ${ }^{24}$ This process involves explicit calculation of the Jacobians for every GRIPS measurement. Here we briefly describe the mathematical basis for the analysis and discuss simulations verifying the feasibility of this measurement approach.

We will use the scene radiance measured by the nadir viewing GRIPS sensor to infer the state of certain atmospheric parameters. Like any measurement, the scene radiance is imperfectly known, and the measurement can be expressed as:

$$
\boldsymbol{y}=F(\boldsymbol{x}, \boldsymbol{b})+\boldsymbol{e}
$$

where $\boldsymbol{y}$ is the vector of measured radiance, $F$ is the forward model function, $\boldsymbol{x}$ is the state vector we wish to infer, $\boldsymbol{b}$ is a vector of model parameters not contained in $\boldsymbol{x}$, and $\boldsymbol{e}$ is the measurement error vector. To simplify the following discussion we assume that all parameters important to the calculation of $\boldsymbol{y}$ are contained in $\boldsymbol{x}$. For the detailed error analysis study performed for GRIPS, $\boldsymbol{x}$ includes pressure, temperature, and interfering species contributions. To begin we linearize about a reference state, $x_{0}$, using a Taylor expansion and retain only first order terms to obtain:

$$
\boldsymbol{y}=F\left(\boldsymbol{x}_{0}\right)+\left(\boldsymbol{x}-\boldsymbol{x}_{0}\right) \boldsymbol{K}_{x}+\boldsymbol{e}
$$

The derivative gives the sensitivity of the measurement to $\boldsymbol{x} . \boldsymbol{K}_{x}$ is the derivative matrix (a matrix of Jacobians), the rows of which give the signal weighting to each of the state parameters. Equation (1) provides a useful tool for understanding sensitivities and error propagation $\left(\right.$ Rodgers $\left.^{24}\right)$.

Retrieving atmospheric parameters from a set of measurements, $\boldsymbol{y}$, is a problem of solving a set of linear equations similar to (1). However, for non-linear well posed problems, the solution procedure is iterated, updating $\boldsymbol{K}_{\boldsymbol{x}}$ between iterations. The problem is ill posed for GRIPS because the number of independent measurements is less than the number of state parameters being retrieved. Thus, we introduce a-priori data to constrain the solution. The GRIPS retrieval system will assume pressure and temperature from ancillary sources, for example NCEP reanalysis (Saha et al., ${ }^{25}$ ). The NCEP reanalysis may also be used to initialize the $\mathrm{H}_{2} \mathrm{O}$ profiles. A-priori data for $\mathrm{CO}, \mathrm{CO}_{2}, \mathrm{CH}_{4}$, and $\mathrm{N}_{2} \mathrm{O}$ may be obtained from global chemical data, e.g. GEOS-Chem (Bey et al. ${ }^{26}$ ).

The a-priori data are included as virtual measurements leading to a solution (the maximum a posteriori solution), $\boldsymbol{x}_{\boldsymbol{m}}$, which is a weighted combination of remote sensing data and a-priori:

$$
\boldsymbol{x}_{\boldsymbol{m}}=\left[\boldsymbol{S}_{a}^{-1}+\boldsymbol{K}_{x}^{T} \boldsymbol{S}_{e}^{-1} \boldsymbol{K}_{x}\right]^{-1}\left[\boldsymbol{S}_{a}^{-1} \boldsymbol{x}_{a}+\boldsymbol{K}_{x}^{T} \boldsymbol{S}_{e}^{-1} \boldsymbol{y}\right],
$$

where $\boldsymbol{x}_{a}$ is the a-priori state vector, $\boldsymbol{S}_{a}$ is the a-priori covariance matrix and $\boldsymbol{S}_{e}$ is the measurement error covariance matrix (for this study this is simply a diagonal matrix with diagonal elements equal to the square of the measurement noise). The term in the denominator is the covariance matrix of the solution. Equation 2 can be rewritten in terms of a deviation from $\boldsymbol{x}_{a}$ :

$$
\boldsymbol{x}_{\boldsymbol{m}}=\boldsymbol{x}_{a}+\boldsymbol{S}_{a} \boldsymbol{K}_{x}^{T}\left[\boldsymbol{K}_{x} \boldsymbol{S}_{a} \boldsymbol{K}_{x}^{T}+\boldsymbol{S}_{e}\right]^{-1}\left[\boldsymbol{y}-\boldsymbol{K}_{x} \boldsymbol{x}_{a}\right]
$$

Defining $\mathbf{G}=\boldsymbol{S}_{a} \boldsymbol{K}_{x}^{T}\left[\boldsymbol{K}_{x} \boldsymbol{S}_{a} \boldsymbol{K}_{x}^{T}+\boldsymbol{S}_{e}\right]^{-1}$ and $\boldsymbol{A}=\boldsymbol{G} \boldsymbol{K}_{x}$, from Worden et al. (2010) the retrieval may be written as:

$$
\boldsymbol{x}_{\boldsymbol{m}}=\boldsymbol{x}_{a}+\boldsymbol{A}\left[\boldsymbol{x}-\boldsymbol{x}_{a}\right]+\boldsymbol{G e}
$$

Equation (4) is used in this work to assess GRIPS ability to measure the true atmospheric state, $x$. The closer the rows of $\boldsymbol{A}$ approach a delta function (diagonal value of 1 ) and the smaller is $\boldsymbol{e}$, the more accurate is the measurement, $\boldsymbol{x}_{m}$. Nadir viewing sensors such as GRIPS typically exhibit smooth averaging kernels with 1 to 3 independent pieces of information for profiling (Pan et al., ${ }^{27}$; Connor et al., ${ }^{28}$; Worden et al., ${ }^{29}$ ). A measure of the number of independent pieces of information contained in a retrieved profile is given by the trace of the matrix $\boldsymbol{A}$. 
We have performed a detailed error analysis using the methodology discussed above. Clear sky performance of GRIPS was simulated using the Linepak forward model (Gordley et al, ${ }^{30}$ ). Measurement errors were simulated assuming uncertainties of $10 \%$ for water vapor, $2 \mathrm{~K}$ for temperature, and $0.3 \%$ for pressure. The simulations assumed an overhead Sun with albedo of 0.1 and 0.02 for a $100 \mathrm{~s}$ observation averaged over ten observations. These results are summarized in Table 3. Performance for nighttime observations of $\mathrm{N}_{2} \mathrm{O}$ and $\mathrm{CO}$ from the 3.88 and $4.64 \mu \mathrm{m}$ channels are similar to that shown for the 0.02 albedo case. Performance for ocean glint observations is likely to be at least as good as that shown for 0.1 albedo case, but will require less integration time. Such timing adjustments will be performed onboard.

Figures 6 and 7 show representative averaging kernels and retrieval examples for overhead Sun and albedo of 0.1 for $\mathrm{CO}, \mathrm{CO}_{2}$, and $\mathrm{CH}_{4}$. The signals used in the analysis are combinations of all paths traveled by photons collected at the instrument and the column abundance estimates are for the mean photon path. Thus, these estimates are accurate for cloud free scenes with low-moderate aerosol loading where multiple scattering and backscatter from clouds and aerosol can be ignored. Depending on confidence of the aerosol measurements and inferences of aerosol optical properties, correction factors may be applied to account for fractional cloud cover and aerosol backscatter. Comprehensive studies will be performed early in phase A to refine channel selection and to investigate various regularization methods as well as impacts due to spectroscopy, solar spectrum errors, line mixing, and other forward model errors.

\section{SUMMARY}

GRIPS is a new instrument concept that takes advantage of the compact yet highly accurate gas-filter correlation radiometry technique to make carbon gas measurements from geostationary orbit. The gas-filter technique is well understood, and has been used from low earth orbit (MOPITT, HALOE) but not from geostationary orbit. All of the GRIPS gas measurements are in the short wave infrared bands (SWIR). The unique quad telescope design allows the instrument to generate four images of the surface, one through the vacuum cell and three others through cells with different target gas pressures. Images are co-aligned using software using techniques developed for other NASA missions.

The carbon gases $\mathrm{CO}_{2}, \mathrm{CH}_{4}$ and $\mathrm{CO}$ are linked to fires and urban pollution. It makes sense then to include aerosol measurements as well. Our quad telescope system can easily accommodate aerosol bands in the visible and nearinfrared. Aerosol measurements have two advantages, (1) they provide context and source generation information for the carbon gases (2) they allow us to better model the small measurement interference from aerosols. In addition to aerosols we will also make a total column water measurement. Although the Advanced Baseline Imager in GEO will also make measurements at MODIS aerosol wavelengths (see Remer et al., 2005), if GRIPS has its own aerosol measurements we can be assured of coincident scans. 
Table 3. Performance Estimates for $100 \mathrm{~s}$ event **

\begin{tabular}{|c|c|c|c|c|c|c|c|c|c|c|c|c|}
\hline \multirow[b]{2}{*}{ Parameter } & \multicolumn{6}{|c|}{$\begin{array}{l}\text { Day-Land } \\
\text { (0.1 albedo) }\end{array}$} & \multicolumn{6}{|c|}{$\begin{array}{l}\text { Day-Ocean } \\
\text { (0.02 albedo) }\end{array}$} \\
\hline & DOF & & & reci & & & DOF & & & recis & & \\
\hline & & I & $\mathrm{T}$ & W & RSS & Avg & & I & $\mathrm{T}$ & W & RSS & Avg \\
\hline CO column & 2.5 & 3.1 & 2.1 & 1.5 & 4.0 & 1.3 & 2.4 & 5.2 & 2.1 & 2.2 & 6.0 & 1.9 \\
\hline $\mathrm{CO}_{2}$ column & 1.3 & 0.5 & 0.3 & 0.2 & 0.7 & 0.2 & 1.0 & 0.8 & 0.3 & 0.3 & 1.0 & 0.3 \\
\hline $\mathrm{CH}_{4}$ column & 1.7 & 0.6 & 0.4 & 0.0 & 0.8 & 0.2 & 1.0 & 0.9 & 0.4 & 0.0 & 1.0 & 0.3 \\
\hline $\mathrm{N}_{2} \mathrm{O}$ column & 1.1 & 0.8 & 0.5 & 0.0 & 1.0 & 0.3 & 0.9 & 0.9 & 0.4 & 0.0 & 1.0 & 0.3 \\
\hline $\mathrm{O}_{2}$ column & 1.0 & 0.2 & 0.0 & 0.0 & 0.4 & 0.1 & 1.0 & 0.3 & 0.1 & 0.0 & 0.4 & 0.1 \\
\hline $\mathrm{CO}(3-9 \mathrm{~km})$ & 0.9 & 6.6 & 4.8 & 1.3 & 8.3 & 2.6 & 0.9 & 6.9 & 4.6 & 1.4 & 8.4 & 2.7 \\
\hline $\mathrm{CO}_{2}(3-9 \mathrm{~km})$ & 0.5 & 1.4 & 0.5 & 0.1 & 1.5 & 0.5 & 0.4 & 1.5 & 0.4 & 0.2 & 1.6 & 0.5 \\
\hline $\mathrm{CH}_{4}(3-9 \mathrm{~km})$ & 0.5 & 2.2 & 0.4 & 0.0 & 2.3 & 0.7 & 0.5 & 2.3 & 0.4 & 0.0 & 2.4 & 0.7 \\
\hline $\mathrm{CO}(<3 \mathrm{~km})$ & 0.8 & 7.7 & 6.0 & 3.1 & 10.2 & 3.2 & 0.7 & 11.5 & 5.5 & 3.9 & 13.3 & 4.2 \\
\hline $\mathrm{CO}_{2}(<3 \mathrm{~km})$ & 0.5 & 1.4 & 0.5 & 0.7 & 1.7 & 0.5 & 0.4 & 1.7 & 0.4 & 0.6 & 1.9 & 0.6 \\
\hline $\mathrm{CH}_{4}(<3 \mathrm{~km})$ & 0.6 & 2.2 & 0.5 & 0.1 & 2.3 & 0.7 & 0.4 & 2.9 & 0.4 & 0.0 & 2.9 & 0.9 \\
\hline
\end{tabular}

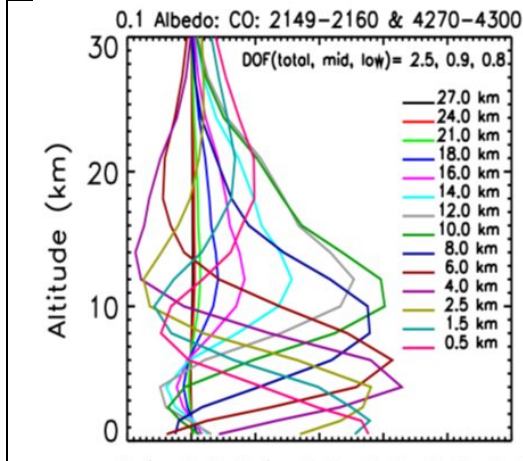

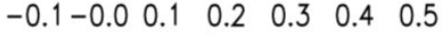

Averoging Kernel
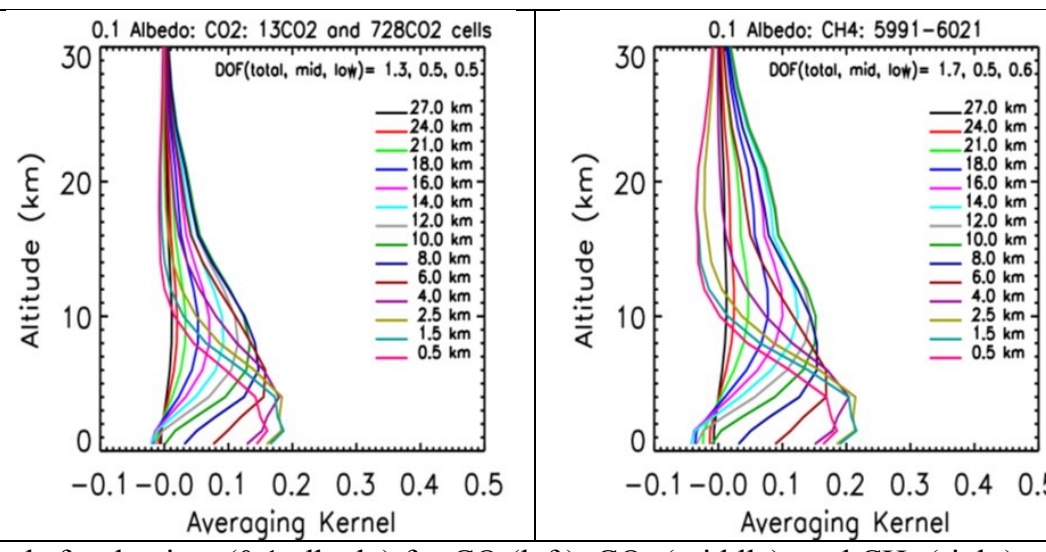

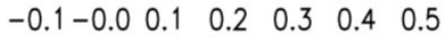
Averoging Kernel

Figure 6. Representative averaging kernels for daytime ( 0.1 albedo) for $\mathrm{CO}$ (left), $\mathrm{CO}_{2}$ (middle), and $\mathrm{CH}_{4}$ (right).
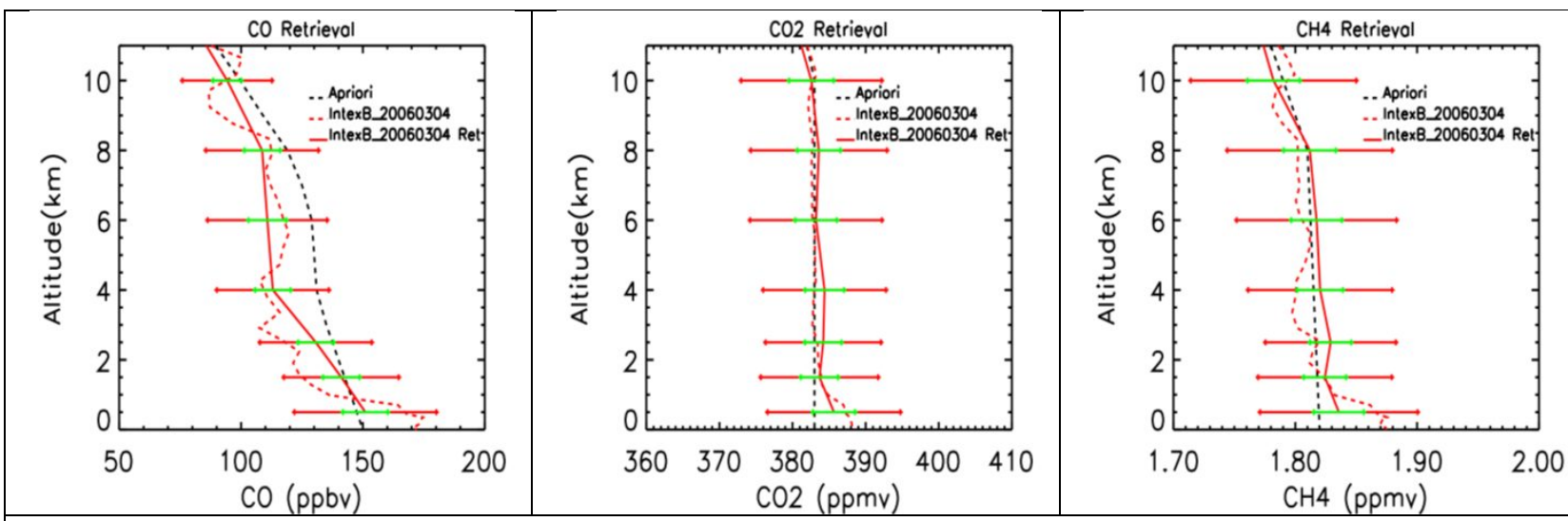

Figure 7. Example retrievals for daytime (0.1 albedo) for $\mathrm{CO}$ (left), $\mathrm{CO}_{2}$ (middle), and $\mathrm{CH}_{4}$ (right). Horizontal lines indicate 1 sigma uncertainty, red for single $100 \mathrm{~s}$ event, green for 10 event average. 


\section{References}

[1] IPCC, "Intergovermental Panel on Climate Change Report," (2007)

[2] Crisp, D., C. E. Miller, and P. L. DeCola "NASA Orbiting Carbon Observatory: measuring the column averaged carbon dioxide mole fraction from space," Journal of Applied Remote Sensing, 2, (2008)

[3] Crisp, D., et al." "The orbiting carbon observatory (OCO) mission," Trace Constituents in the Troposphere and Lower Stratosphere, edited by J. P. Burrows and A. M. Thompson, 700-709, (2004)

[4] Miller, C. E., et al. (2007), "Precision requirements for space-based X(CO2) data," J. Geophysical Res, 112(D10).

[5] Dlugokencky, E. J., E. G. Nisbet, R. Fisher, and D. Lowry, "Global atmospheric methane: budget, changes and dangers," Philosophical Transactions of the Royal Society a-Mathematical Physical and Engineering Sciences, 369(1943), 2058-2072, (2011)

[6] Howarth, R. W., R. Santoro, and A. Ingraffea. "Methane and the greenhouse-gas footprint of natural gas from shale formations," Climatic Change, doi:10.1007/s10584-011-0061-5, (2011).

[7] Thompson, A. M., "The oxidizing capacity of the Earth's atmosphere: Probable past and future changes," Science, 256, 1157-1165, (1992).

[8] Thompson, A. M., and R. J. Cicerone "Possible perturbations to atmospheric CO, CH4, and OH," J. Geophy. Res., 91(10), 853-864, (1986)

[9] Cooper, O. R., et al., "Increasing springtime ozone mixing ratios in the free troposphere over western North America," Nature, 463(7279), 344-348, (2010).

[10] Jaffe, D., "Relationship between Surface and Free Tropospheric Ozone in the Western U.S," Environmental Science and Technology, 45, 432-438, (2011)

[11] Lin, M., A. M. Fiore, L. W. Horowitz, O. R. Cooper, V. Naik, J. Holloway, B. J Johnson, A. M. Middlebrook, S. J. Oltmans, I. B. Pollack, T. B. Ryerson, J. X. Warner, C. Wiedinmyer, J. Wilson, and B. Wyman. "Transport of Asian ozone pollution into surface air over the western United States in spring," J. Geophys. Res., 117, doi:10.1029/2011JD016961, (2012).

[12] Bellouin, Nicolas, et al. "Global Estimate of Aerosol Direct Radiative Forcing from Satellite Measurements." Nature ,438, 1138-1141 doi: 10.1038/nature04348, (2005)

[13] Rosenfield, D., and I. M. Lensky, "Satellite-based insights into precipitation formation processes in continental and maritime convective clouds." Bull. Amer. Meteor. Soc., 79, 2457-2476, (1998)

[14] Twomey, S. A., "The influence of pollution on the shortwave albedo of clouds." J. Atmos. Sci., 34, 1149-1152, (1977)

[15] Kaufman, Y., D. Tanré, and O. Boucher, “A satellite view of aerosols in the climate system.” Nature, 419, 215-223, (2002).

[16] Remer, L., et al, “The MODIS aerosol algorithm, products and validation”, J. Atmos. Sci., 62, 947-973, (2005)

[17] Frankenberg, C., et al. "Assessing methane emissions from global space-borne observations," Science, 308, doi:10.1126/science.1106644, (2005). 
[18] Kaufman, Y. D. Tanré, L. A. Remer, E. Vermote, A. Chu, and B. N. Holben "Operational remote sensing of tropospheric aerosol over land from EOS Moderate Resolution Imaging Spectroradiometer.” J. Geophys. Res., 102, 17 051-17 067, (1997).

[19] Abel, P., P. Ellis, J. Houghton, G. Peckman, C. Rogers, S. Smith, and E. Williamson, "Remote sounding of atmospheric temperature from satellites II. The selective chopper radiometer for Nimbus D," Proc. Roy. Soc. London, 320A, 35-55, (1970)

[20] Drummond, J. R., J. Houghton, G. Peskett, C. Rogers, M. Wale, J. Whitney, and E. Williamson, "The stratospheric and mesospheric sounder on Nimbus 7," Philos. Trans. Roy. Soc. London, 296A, 219-241, (1980)

[21] Tolton, B. T., and J. Drummond "Measurement of the atmospheric carbon monoxide column with a ground-based length modulated radiometer” Appl. Opt., 38, 1897-1909, (1999).

[22] Deeter, M. N., H. M. Worden, J. C. Gille, D. P. Edwards, D. Mao, and J. R. Drummond. "MOPITT multispectral CO retrievals: Origins and effects of geophysical radiance errors," J. Geophys. Res., 116, D15303, doi:10.1029/2011JD015703, (2011).

[23] Mitchell, R. M., and D. M. O'Brien. "Error estimates for passive satellite measurement of surface pressure using absorption in the A band of oxygen, "J. Atmos. Sci., 44, 1981-1990, (1987).

[24] Rodgers, C. D. [Inverse Methods for Atmospheric Sounding: Theory and Practice], World Scientific Publishing Co. Ltd., Hackensack, NJ, (2000).

[25] Saha, S., et al ,"The NCEP Climate Forecast System Reanalysis,” Bull. Amer. Meteor Soc., 91, 1015-1057, (2010).

[26] Bey, I., D. J. Jacob, R. M. Yantosca, J. A. Logan, B. Field, A. M. Fiore, Q. Li, H. Liu, L. J. Mickley, and M. Schultz. "Global modeling of tropospheric chemistry with assimilated meteorology: Model description and evaluation," J. Geophys. Res., 106, 23,073-23,096, (2001)

[27] Pan, L., J. C. Gille, D. P. Edwards, P. L. Bailey, and C. D. Rodgers "Retrieval of tropospheric carbon monoxide for the MOPITT experiment,” J. Geophys. Res., 103, 32277-32290, . (1998)

[28] Connor, B. J., H. Boesch, G. Toon, B. Sen, C. Miller, and D. Crisp. , Orbiting Carbon Observatory: Inverse method and prospective error analysis, J. Geophys. Res., 113 (D05305), doi:10.1029/2006JD008336., (2008)

[29] Worden, H. M., et al. "Observations of near-surface carbon monoxide from space using MOPITT multispectral retrievals,", J. Geophys. Res., 115, doi:10.1029/2010JD014242, (2010).

[30] Gordley, L. L., B. T. Marshall, and D. A. Chu. Linepak, "Algorithms for modeling spectral transmittance and radiance," J. Quant. Spectrosc. Radiat. Transfer 52 (5), 563-580, doi:10.1016/0022-4073(94)90025-6, (1994). 